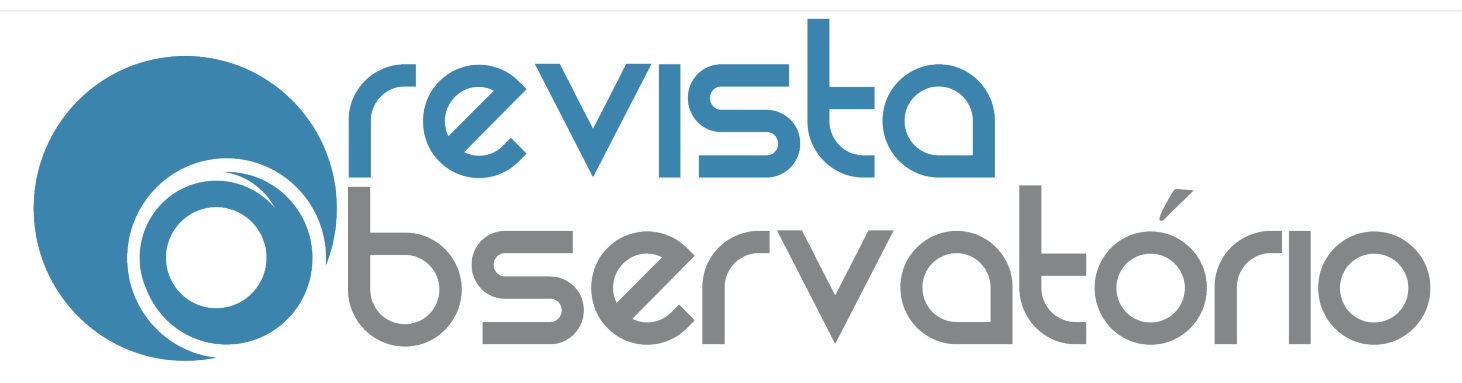

ISSN n² 2447-4266

Vol. 3, n. 6, Outubro-Dezembro. 2017

DOI: http://dx.doi.org/10.20873/uft.2447-4266.2017v3n6p25

\title{
FORMAÇÃO, COMUNICAÇÃO E EDUCAÇÃO PÓS-BOLONHA: um novo futuro?
}

O perigo do passado era que os homens se tornassem escravos. O perigo do futuro é que os homens se tornem autômatos.

Erich Fromm

Chegamos a conclusão do terceiro ano editorial da Revista Observatório com chave de ouro: durante esse período tivemos diversos avanços na estrutura editorial, que permitiu pensar a revista além do que é feito no momento. Tivemos a agregação de novos atores: na revisão linguística (em português, inglês, espanhol e francês); na edição de mídias sociais que tornou nossa página no Facebook mais visível (passando de 2 mil curtidas!); na edição de metadados, onde voluntários que se debruçam para melhorar os mecanismos de pesquisa na revista e na indexação; e, novos indexadores, que atualizam o conteúdo da revista nos vários espaços de presença da revista. Todo esse sistema alimentado por voluntários dos vários cantos do Brasil e do Exterior!

Nesse número publicamos dois dossiês temáticos: o primeiro intitulado Processos formativos, Comunicação e Educação Pós-Bolonha, organizado pelos professores Luis Carlos Martins de Almeida Mota (Coimbra, Portugal) e Francisco Gilson Rebouças Porto Junior (Palmas, Brasil); o segundo intitulado Mulher e Mídia 2, organizado pelos professores Sandra de Souza Machado (Brasília, DF) e Cynthia Mara Miranda (Palmas, Brasil), dá continuidade a temática da mulher e a presença na mídia. 


\section{Obrevisto}

ISSN n² 2447-4266

Vol. 3, n. 6, Outubro-Dezembro. 2017

DOI: http://dx.doi.org/10.20873/uft.2447-4266.2017v3n6p25

No Dossiê Processos formativos, Comunicação e Educação pós-Bolonha se problematiza a evolução da educação, da comunicação e das políticas, em geral, e o ensino superior, em particular, num quadro de globalizações que exige um esforço de compreensão perante o imbricado das transformações, nem sempre congruentes entre si. Trata-se de um contexto complexo em face das múltiplas perspectivas de análise, das variáveis que o condicionam e da produção científica que sobre ele se tem debruçado.

A globalização - em bom rigor, globalizações - ocorre em ritmo e intensidade diferenciada, em diferentes regiões do globo e nas diversas vertentes da vida social. Processos sociais complexos que geram tensões e conflitos. A perda de centralidade do Estado-nação compagina-se com a emergência de entidades econômicas-políticas regionais de natureza supranacional (por exemplo, MERCOSUL, NAFTA ou União Europeia). Entidades de iniciativa dos Estados com o objetivo de estes ampliarem a sua influência nas dinâmicas de globalização. Processos que têm conduzido à afirmação de organizações (nacionais ou transnacionais) onde as elites e os peritos dominam e o escrutínio democrático dos cidadãos está ausente - exemplo, a Organização Mundial do Comércio, bancos centrais, instituições reguladoras.

Busca-se, nesse quadro, problematizar uma agenda de debate voltada para a configuração de áreas-chave no campo da cooperação internacional em matéria de educação, tais como: acesso, qualidade e equidade. São constituídos acordos, estratégias e políticas, os quais traduzem uma agenda de cooperação, tendo a educação um papel fundamental nessa seara. Nesse campo, várias estratégias e iniciativas se destacam, tais como o estabelecimento da Rede Universitária do BRICS, o reconhecimento mútuo dos títulos e diplomas do ensino superior, entre outros. Essas estratégias, acordos e políticas se inserem no contexto de reforço da cooperação intrablocos regionais, tendo como caso paradigmático o Processo de Bolonha europeu, cujo documento-símbolo, a Declaração de Bolonha (1999), volta-se à afirmação de uma área europeia de ensino superior e de investigação, cujos antecedentes de formação 


\section{Obseristo}

ISSN n² 2447-4266

Vol. 3, n. 6, Outubro-Dezembro. 2017

DOI: http://dx.doi.org/10.20873/uft.2447-4266.2017v3n6p25

remontam ao final da década de oitenta e noventa do século $X X$, com a elaboração dos documentos Magna Charta Universitatum (1988) e a Declaração de Sorbonne (1998).

Neste contexto as políticas de educação e comunicação já não são assunto exclusivo do Estado-nação. As análises da relação entre os processos de globalização e os fenômenos educativos têm sido marcadas, fundamentalmente, por duas perspectivas. Uma encara a expansão mundial dos sistemas educativos e comunicacionais como parte integrante de um processo longo e mais vasto de globalização cultural que inclui a disseminação do Estadonação e valores como o progresso, a igualdade e os direitos humanos. A outra acentua que a relação entre globalização e a educação se processa com a mediação do Estado, dependendo do posicionamento deste no sistema mundial e do intrincado processo de relações sociopolítico-institucionais do contexto nacional. Uma terceira leitura, adotando um posicionamento de natureza histórico-social, destaca a importância dos modelos de reforma e de desenvolvimento serem sempre contextualizados no plano cultural, intelectual, político ou ideológico, nacionais.

Com iniciativas diferenciadas e diversificadas, estudos e publicações, estas organizações constituem hoje fóruns de concepção e globalização de uma agenda para a educação que fixa prioridades e formas de colocação dos problemas, configura o pensamento e ação política, nos planos continental e transcontinental, e define mecanismos de regulação dos sistemas de ensino, desempenhando um papel não despercebido no plano das políticas educativas nacionais. Nesta perspectiva, adquire especial pertinência a discussão e problematização que o dossiê "Processos formativos, Comunicação e Educação pós-Bolonha" faz.

Abrindo o dossiê, temos o artigo A FORMAÇÃO DE PROFESSORES EM PORTUGAL NO QUADRO DO ESPAÇO EUROPEU DE ENSINO SUPERIOR, de Luis Carlos Martins de Almeida Mota e António Gomes Ferreira, onde os autores discutem as alterações ocorridas em fim do Século XX nos processos de formação de professores. Os autores fazem uso de revisão bibliográfica, análise documental de um conjunto diversificado de fontes entre os 


\section{Observisto}

ISSN n² 2447-4266

Vol. 3, n. 6, Outubro-Dezembro. 2017

DOI: http://dx.doi.org/10.20873/uft.2447-4266.2017v3n6p25

documentos das instituições internacionais e supranacionais, de grupos de trabalho e plataformas intergovernamentais - estudos, relatórios, inquéritos e seus resultados, programas, projetos, tratados, etc. -, bem como a produção legislativa sobre problemática, dos últimos governos de Portugal, no sentido de clarificar princípios e opções de política educativa no domínio da formação de professores, nomeadamente ao nível do recrutamento, do perfil profissional e da organização dos planos de estudo e da oferta educativa.

No artigo ENQUADRAMENTO HISTÓRICO LEGAL DO PROCESSO DE BOLONHA E O SEU IMPACTO NO SISTEMA DE ENSINO SUPERIOR PORTUGUÊS, Ana Souto e Melo propõe-se a analisar o impacto do Processo de Bolonha nas políticas do sistema de Ensino Português, ao nível histórico legal. Neste sentido, discute alguns dos aspectos que marcaram o percurso histórico e processual da implementação do Processo de Bolonha, fazendo referência aos diversos encontros de reflexão efetivados pelos vários estados-membros desenvolvendo, ainda, as principais ideias traçadas e a sua repercussão no sistema de ensino português.

Já Elvira Gomes dos Reis, discute no artigo O ENSINO SUPERIOR EM CABO VERDE E OS DESAFIOS DO PROCESSO DE BOLONHA os esforços de aproximação do Ensino Superior de Cabo Verde ao Acordo de Bolonha. A autora problematiza a importância de uma competência bi/plurilingue, hoje e no contexto da globalização, partindo do pressuposto que ela é o motor da internacionalização das competências e, consequentemente, de realização pessoal e social à escala global, visto que ela tem o poder de fomentar a mobilidade e facilitar a intercompreensão, alargando a sua visão do mundo e facilitando a internacionalização das suas competências.

No artigo A DECLARAÇÃO DE BOLONHA E O REFORÇO DA ABERTURA DO ENSINO SUPERIOR A NOVOS PÚBLICOS: perceções de pessoas adultas que frequentam a Universidade de Coimbra, Isabel Moio, Luís Alcoforado e Cristina Coimbra Vieira discutem o regime de acesso de pessoas adultas ao ensino superior, que provocou um acréscimo muito significativo de entradas, nas Universidades e Institutos Politécnicos, para maiores de vinte e três anos. No 


\section{Obseristo}

ISSN n² 2447-4266

Vol. 3, n. 6, Outubro-Dezembro. 2017

DOI: http://dx.doi.org/10.20873/uft.2447-4266.2017v3n6p25

texto, os autores apresentam um estudo com estes estudantes, que frequentam a Universidade de Coimbra, realizado através de questionário com perguntas fechadas e abertas, seguido de focus group, onde se pode compreender a importância que a oportunidade de acesso e a experiência vivida, enquanto estudantes têm para estas pessoas.

No artigo FORMANDO PESQUISADORES PÓS-BOLONHA EM PORTUGAL: relações entre a formação de graduação e o campo da pesquisa/investigação, Francisco Gilson Rebouças Porto Junior e Nelson Russo de Moraes tentam compreender as relações estabelecidas entre formação inicial (primeiro ciclo) e a pesquisa/investigação, partindo de entrevistas com professores e gestores em universidades portuguesas. A percepção dos a(u)tores sobre esse movimento nos ajuda a vislumbrar elementos constitutivos dos processos envolvidos nas mudanças curriculares. Os autores apontam que o Processo de Bolonha marcou a Europa e o mundo com a robustez de propostas formativas mais condensadas que deram rápidas respostas às demandas profissionais da sociedade, o que fez com que surgissem questionamentos sobre a maturidade científica dos mestres e doutores formados pelo desdobramento deste processo e sobre a fragilidade metodológica absorvida pelos profissionais de primeiro ciclo.

Já no artigo A CONVERGÊNCIA MIDIÁTICA E AS TECNOLOGIAS MÓVEIS PÓS-BOLONHA: novas práticas sociais, José Lauro Martins e Valdirene Cassia da Silva discutem as práticas sociais e as novas formas de mobilidade disponíveis pela concepção de espaço/tempo, introduzida pelas tecnologias móveis no Processo de Bolonha - resultado da convergência midiática que engendrou novos comportamentos e mudanças nas relações sociais.

No artigo MAPEAMENTO DOS ESTUDOS SOBRE A FORMAÇÃO DE PROFESSORES NO ÂMBITO DO PROCESSO DE BOLONHA EM PORTUGAL, Elaine Jesus Alves, Bento Duarte da Silva e Raiane da Silveira da Silva mapeam as pesquisas realizadas em Portugal sobre a formação de professores no contexto do Processo de Bolonha com vista a compreender as implicâncias que uma reforma no ensino superior desta amplitude pode impactar nos trabalho 


\section{Obseristo}

ISSN n² 2447-4266

Vol. 3, n. 6, Outubro-Dezembro. 2017

DOI: http://dx.doi.org/10.20873/uft.2447-4266.2017v3n6p25

docente dos professores. A metodologia utilizada foi revisão sistemática utilizando pesquisa nos Repositórios Científicos de Acesso aberto de Portugal (RCAAP) que agrega metadados das principais instituições universitárias e de pesquisa daquele país.

Em UNIVERSIDADE E CRISE INSTITUCIONAL: perspectivas de uma formação humana, Maria José de Pinho busca fazer uma reflexão da transição do paradigma conservador para paradigma emergente e sua influência no contexto da universidade do século XXI na perspectiva de uma visão complexa da realidade contemporânea. Também Busca contextualizar a universidade como protagonista na construção de um novo paradigma para educação, bem como o repensar das instituições de ensino superior a partir do Processo de Bolonha tendo em vista uma educação superior voltada para competitividade e para a competência profissional.

No artigo REFLEXÕES EM TORNO DO BRINCAR EM CONTEXTOS DE EDUCAÇÃO DE INFÂNCIA, Ana Sarmento Coelho e Vera Maria do Vale refletem acerca do brincar em contextos de educação de infância em Portugal, revisitando algumas linhas de pesquisa que têm sido desenvolvidas por diversos autores, colocando em contra ponto os discursos vigentes e o seu compromisso nas práticas, pelos educadores de infância.

Finalizando o dossiê, no artigo CONHECIMENTO E ORGANIZAÇÃO: indicativos pósBolonha de uma sociedade em construção, Suzana Gilioli Nunes, Francisco Gilson Rebouças Porto Junior e Nelson Russo de Moraes voltam-se para as questões relacionadas ao conhecimento organizacional e sua gestão, pós-Bolonha, mas não se reduzindo apenas a isso. Por meio da análise de diversos autores, discutem o conhecimento organizacional e sua aplicabilidade. Concluem que a reorganização do conhecimento trás consigo a tessitura de novos modelos organizacionais, de novos projetos de processos produtivos e de novos projetos de produtos finais, alinhados aos novos determinantes de mercado. 


\section{Obrevisto}

ISSN n² 2447-4266

Vol. 3, n. 6, Outubro-Dezembro. 2017

DOI: http://dx.doi.org/10.20873/uft.2447-4266.2017v3n6p25

No dossiê Mulher e Mídia 2, problematizam-se questões referentes a presença da mulher nos diversos espaços comunicacionais. O direito humano à comunicação é condição sine qua non para a construção de sociedades verdadeiramente democráticas. Muitas questões estão envolvidas para a garantia desse direito como, por exemplo, garantir que os meios de comunicação ofereçam representações da coletividade que contemplem toda a sua diversidade. Na prática, contudo o que prevalece são representações textuais, imagéticas e audiovisuais padronizadas para atender os interesses financeiros das empresas de comunicação e não ao interesse das cidadãs e dos cidadãos.

As representações das mulheres nos meios de comunicação - que motivam a organização do presente dossiê Mulher e Mídia - em diferentes formatos e produtos, como filmes, animações, séries de TV e em plataformas da Internet, ou mesmo as notícias nas mídias, têm sido questionadas, cotidianamente, pelos movimentos feministas por reproduzir a desigualdade entre os gêneros. Há tratados internacionais, como a Plataforma de Ação de Pequim (1995), que destacam a importância da atuação dos meios de comunicação para a igualdade de gênero e, para isso, é necessário fomentar uma imagem equilibrada e não estereotipada das mulheres. Iniciativas para transformar essa realidade têm sido capitaneadas pela sociedade civil e movimentos feministas que, ao protestar contra a sub-representação da imagem das mulheres na mídia, cobram do Estado a adoção de políticas para a democratização da Comunicação.

O Dossiê Mulher e Mídia 2, que assim como o primeiro é também organizado por Cynthia Mara Miranda e Sandra de Souza Machado, nesse sentido, acolheu artigos sobre as representações das mulheres nos cinemas, na TV, nas séries, e na produção audiovisual infantil, na política, nos esportes, e também como fonte de notícias relacionadas à violência contra as mulheres e ao feminícidio, crimes esses que são cometidos e amplamente publicizados pelos meios de comunicação latino-americanos. 


\section{Obrevisto}

ISSN n² 2447-4266

Vol. 3, n. 6, Outubro-Dezembro. 2017

DOI: http://dx.doi.org/10.20873/uft.2447-4266.2017v3n6p25

Este Dossiê reúne oito artigos que promovem reflexões sobre as representações das imagens das mulheres em vários produtos midiáticos, e aponta para a necessidade de repensar tais representações e estereotipias, a fim de torná-las mais comprometidas com o avanço da igualdade entre os gêneros. Há, ainda, a entrevista com a dramaturga, atriz e pedagoga teatral argentina Ana Woolf, uma das fundadoras do Magdalenas $2^{a}$ Generación - o teatro das mulheres, braço latino-americano do Magdalena Project.

Nos anos 1970, surgiu esse movimento organizado pelas mulheres dramaturgas, a rede Magdalena Project, fundado, entre outras, pela pesquisadora e teatróloga britânica Julia Varley. Desde então, o principal ponto de reunião das Magdalenas é o Odin Teatret, escola de dramaturgia da Dinamarca e uma das principais da Europa. Hoje, o projeto das artes cênicas, multimídia e interdisciplinar, abrange diretoras, pesquisadoras, atrizes e estudantes do teatro e de outras áreas da criação artística, procedentes de mais de 50 países, para mudar ou equilibrar o feminino no cenário teatral e artístico mundial.

O dossiê é aberto com o artigo ESTEREÓTIPOS DE GÊNERO E PAPÉIS-MODELO: \#MaisMulheresMaravilha nos cinemas, Sandra de Souza Machado, que propõe uma reflexão sobre o papel da indústria cinematográfica na produção eurocêntrica que instiga e enraíza estereótipos (interseccionais) femininos de gênero e aponta para a necessidade de mais papéis-modelo positivos e afirmativos para a construção da igualdade de gênero e para as futuras gerações.

Já o artigo REPRESENTAÇÕES DAS GERAÇÕES FEMININAS NA PRODUÇÃO AUDIOVISUAL INFANTIL, Verônica Dantas Meneses, problematiza a produção audiovisual destinada ao público infantil na TV, a partir dos estudos de gênero que trabalham os conceitos de alteridade e diversidade e estudos sobre os processos de inserção da televisão e dos conteúdos audiovisuais na vida cotidiana.

No artigo LUTE COMO UMA MENINA: questões de gênero nas ocupações das escolas de São Paulo em 2016, Ana Paula dos Santos e Cynthia Mara Miranda, é analisado o 


\section{Obseristo}

ISSN n² 2447-4266

Vol. 3, n. 6, Outubro-Dezembro. 2017

DOI: http://dx.doi.org/10.20873/uft.2447-4266.2017v3n6p25

documentário "Lute como uma menina", como uma ferramenta para dar espaço ao discurso das jovens mulheres no movimento secundarista e dar visibilidade às questões de gênero nas ocupações das escolas de São Paulo, em 2016.

Em VIOLÊNCIA CONTRA MULHER NA MÍDIA E OS DES CAMINHOS DA IGUALDADE ENTRE OS GÊNEROS, Cynthia Mara Miranda analisa a representação da violência contra a mulher na mídia para verificar o papel de responsabilidade social dos meios de comunicação na problematização da questão. A pesquisa aponta para a importância da mobilização social na construção de uma comunicação para a igualdade.

Em seu artigo FEMINICÍDIOS NA MÍDIA E DESUMANIZAÇÃO DAS MULHERES, Ana Liése Thurler examina o tratamento dado pela mídia à violência extrema de gênero contra as mulheres, o feminicídio. $\mathrm{O}$ artigo destaca a necessidade da adoção de perspectivas de gênero pelos discursos midiáticos e de registrar os processos vivenciados pelas mulheres na direção de seu maior protagonismo.

No artigo VELHICE, VELHICES: entre (in) visibilidades, ativismos e transgressões, Maria Luiza Martins de Mendonça apresenta reflexões sobre as representações sociais construídas, por meio dos discursos difundidos pela mídia, sobre o envelhecimento feminino, considerando-os a partir da perspectiva teórica que considera a esfera da produção simbólica como um locus de disputa pela fixação dos significados sociais.

Em MEDIOS, MULTIMODALIDAD, GÊNERO Y POLÍTICA: Cristina Fernández de Kirchner en Noticias, Sara Isabel Pérez explora os processos de construção discursiva multimodal da imagem da ex-presidenta da Argentina, Cristina F. de Kirchner, nas capas da Revista Noticias. Ao longo do texto, a autora analisa como se constroem e se reproduzem os significados vinculados aos lugares comuns e as representações e identidades genéricas hegemônicas.

O último artigo do dossiê é ANÁLISE DA VISIBILIDADE E PARTICIPAÇÃO FEMININA NA COBERTURA JORNALÍSTICA DA OLIMPÍADA RIO 2016 REALIZADA PELOS PORTAIS ESPNWE LANCE!, Valquiria Michela John e Elyson Gums, que analisam a cobertura jornalística dedicada 


\section{Obseristo}

ISSN n² 2447-4266

Vol. 3, n. 6, Outubro-Dezembro. 2017

DOI: http://dx.doi.org/10.20873/uft.2447-4266.2017v3n6p25

à mulher no esporte e os papéis a elas atribuídos no contexto da Olimpíada Rio 2016, no momento em que em que todas as atenções se voltam para os esportes e que há uma intensa participação de atletas mulheres.

A defesa da Comunicação para a igualdade a partir de distintas perspectivas temáticas e de abordagens teórico-metodológicas promove a aproximação entre os artigos. Os textos apresentados apontam para linhas de reflexão que revelam esforços coletivos de mulheres na academia, nas artes e nos movimentos sociais, para avançar na efetivação do direito à comunicação e da igualdade de gênero.

Abrindo a seção TEMAS LIVRES, temos o artigo A ECONOMIA DA ATENÇÃO DO ESCÂNDALO POLÍTICO de Helder Prior. Nele o autor procura delinear alguns aspectos que evidenciam a configuração do escândalo político nas sociedades mediatizadas, com especial atenção à exploração do escândalo enquanto artefato mediático.

No artigo O USO DAS FONTES NAS NOTÍCIAS SOBRE O PROCESSO DE IMPEACHMENT: uma análise da cobertura realizada pelos jornais Folha de S. Paulo e A Tarde (BA), Ebida Rosa dos Santos e Liziane Soares Guazina analisam o uso das fontes pelos jornais Folha de S. Paulo e A Tarde durante a cobertura do processo de impeachment de Dilma Rousseff considerando sete dias anteriores a três momentos relevantes de julgamento no Congresso Nacional.

Em PRODUTOS JORNALÍSTICOS PARA TABLETS COMO FERRAMENTAS PEDAGÓGICAS: estudo de caso do Golpe de 1964, Rita de Cássia Romeiro Paulino e Marina Lisboa Empinotti detalham o processo produtivo de um produto jornalístico para tablets-iPad no formato Folio voltado para a Educação. A concepção envolve apuração, checagem de informações, redação, editoração e demais etapas do trabalho do Jornalista, mas pensado para ser aplicado de forma didática em sala de aula, para um público-alvo de ensino fundamental, de 12 a 14 anos.

Já no artigo PADRÕES ESTÉTICOS E ATUAÇÃO PROFISSIONAL DE MULHERES TELEJORNALISTAS: uma pesquisa exploratória, Luis Mauro Sá Martino e Julya Vendite Zancoper 


\title{
Obrevisto
}

ISSN n² 2447-4266

Vol. 3, n. 6, Outubro-Dezembro. 2017

DOI: http://dx.doi.org/10.20873/uft.2447-4266.2017v3n6p25

delineiam alguns aspectos dessa demanda, colocada para as jornalistas, de atingir um determinado padrão hegemônico de beleza no telejornalismo. Esse padrão é discutido a partir do ponto de vista de questões de identidade e poder simbólico.

No artigo DA PORTA AO PORTAL: o espaço como metáfora da narrativa jornalística, Jeana Laura da Cunha Santos confronta dois tempos - o passado e o presente - da produção jornalística, a partir dos lugares para daí investigar o quanto a materialidade do espaço condiciona a narrativa produzida pelos profissionais.

E, finalizando a seção, o artigo EL TIEMPO Y LA COMUNICACIÓN: Nuevos Horizontes, de Marta Pagán Martínez e Renato Dias Baptista analisam o papel da comunicação nos processos de mudança de negócios. Com base na revisão bibliográfica como metodologia, analisa-se a função da comunicação organizacional, a cultura organizacional e a dissonância entre modelos corporativos tradicionais e emergentes.

Na seção ENTREVISTAS, temos a entrevista com a dramaturga, atriz e pedagoga teatral argentina Ana Woolf, intitulada A Segunda Generación das Magdalenas, o Teatro das Mulheres: Entrevista com a dramaturga e atriz argentina Ana Woolf, realizada por Sandra de Souza Machado.

Temos certeza de que você terá muito prazer na leitura e reflexão do novo número da Revista Observatório!

Coimbra/PT, Brasília/DF, Palmas-TO, Outubro de 2017.

\begin{abstract}
Editor adjunto internacional / Associate Editor / Editor Asociado / Comité de rédaction international Luis Carlos Martins de Almeida Mota, Instituto Politécnico de Coimbra, Portugal
\end{abstract}




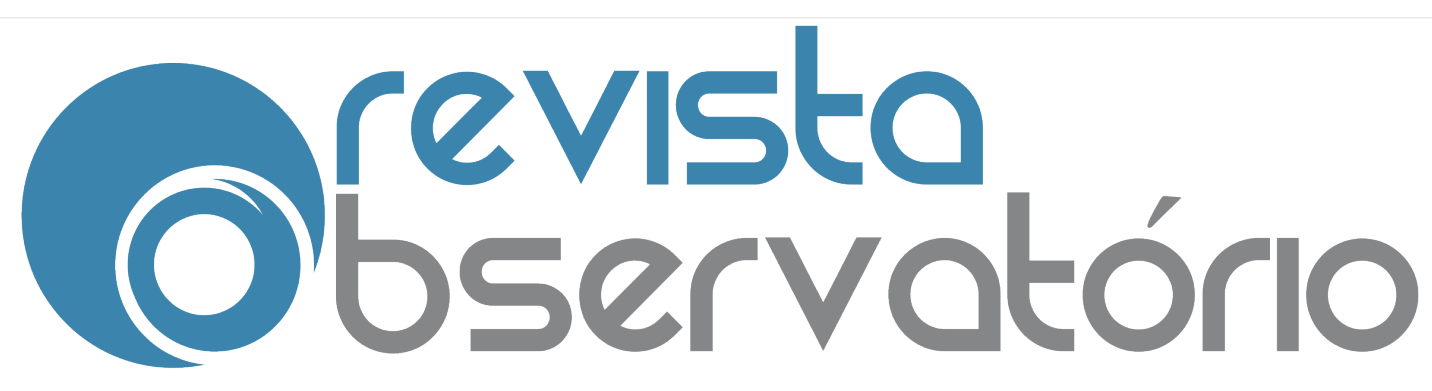

ISSN n² 2447-4266

Vol. 3, n. 6, Outubro-Dezembro. 2017

DOI: http://dx.doi.org/10.20873/uft.2447-4266.2017v3n6p25

Cynthia Mara Miranda Universidade Federal do Tocantins (UFT), Brasil. Sandra de Souza Machado, Universidade de Brasília (UnB), Brasil.

Editor Geral / Chief Editor / Editor general Francisco Gilson Rebouças Porto Junior, Universidade Federal do Tocantins (UFT), Brasil.

\section{Referências}

ALVES, E. J.; SILVA, B. D. DA; SILVA, R. DA S. DA. MAPEAMENTO DOS ESTUDOS SOBRE A FORMAÇÃO DE PROFESSORES NO ÂMBITO DO PROCESSO DE BOLONHA EM PORTUGAL. Revista Observatório, v. 3, n. 6, p. 248-273, 1 out. 2017.

COELHO, A. S.; VALE, V. M. DO. REFLEXÕES EM TORNO DO BRINCAR EM CONTEXTOS DE EDUCAÇÃO DE INFÂNCIA. Revista Observatório, v. 3, n. 6, p. 316-337, 1 out. 2017.

DOS SANTOS, A. P.; MIRANDA, C. M. LUTE COMO UMA MENINA: questões de gênero nas ocupações das escolas de São Paulo em 2016. Revista Observatório, v. 3, n. 6, p. 417-444, 21 maio 2017.

JOHN, V. M.; GUMS, E. ANÁLISE DA VISIBILIDADE E PARTICIPAÇÃO FEMININA NA COBERTURA DA OLIMPÍADA RIO 2016 REALIZADA PELOS PORTAIS ESPNW E LANCE!. Revista Observatório, v. 3, n. 6, p. 557-585, 1 out. 2017.

MACHADO, S. DE S. A Segunda Generación das Magdalenas, o Teatro das Mulheres: Entrevista com a dramaturga e atriz argentina Ana Woolf. Revista Observatório, v. 3, n. 6, p. 728-737, 1 out. 2017.

MACHADO, S. DE S. ESTEREÓTIPOS DE GÊNERO E PAPÉIS MODELO: \#Mais Mulheres Maravilha nos Cinemas. Revista Observatório, v. 3, n. 6, p. 354-386, 1 out. 2017.

MARTÍNEZ, M. P.; BAPTISTA, R. D. EL TIEMPO Y LA COMUNICACIÓN: Nuevos Horizontes. Revista Observatório, v. 3, n. 6, p. 698-727, 1 out. 2017.

MARTINO, L. M. S.; ZANCOPER, J. V. PADRÕES ESTÉTICOS E ATUAÇÃO PROFISSIONAL DE MULHERES TELEJORNALISTAS: uma pesquisa exploratória. Revista Observatório, v. 3, n. 6, p. 658-679, 1 out. 2017.

MELO, A. S. E. ENQUADRAMENTO HISTÓRICO LEGAL DO PROCESSO DE BOLONHA E O SEU IMPACTO NO SISTEMA DE ENSINO SUPERIOR PORTUGUÊS. Revista Observatório, v. 3, n. 6, p. 75-141, 1 out. 2017.

MENDONÇA, M. L. M. DE. VELHICE, VELHICES: entre (in)visibilidades, ativismos e transgressões. Revista Observatório, v. 3, n. 6, p. 497-516, 1 out. 2017.

MENESES, V. D. REPRESENTAÇÕES DAS GERAÇÕES FEMININAS NA PRODUÇÃO AUDIOVISUAL INFANTIL. Revista Observatório, v. 3, n. 6, p. 387-416, 1 out. 2017. 


\section{Observisto}

ISSN n² 2447-4266

Vol. 3, n. 6, Outubro-Dezembro. 2017

DOI: http://dx.doi.org/10.20873/uft.2447-4266.2017v3n6p25

MIRANDA, C. M. VIOLÊNCIA CONTRA A MULHER NA MÍDIA E OS DESCAMINHOS DA IGUALDADE ENTRE OS GÊNEROS. Revista Observatório, v. 3, n. 6, p. 445-464, 1 out. 2017. MOIO, I.; ALCOFORADO, L.; VIEIRA, C. C. A DECLARAÇÃO DE BOLONHA E O REFORÇO DA ABERTURA DO ENSINO SUPERIOR A NOVOS PÚBLICOS: perceções de pessoas adultas que frequentam a Universidade de Coimbra. Revista Observatório, v. 3, n. 6, p. 169-201, 1 out. 2017.

MOTA, L. C. M. DE A.; FERREIRA, A. G. A FORMAÇÃO DE PROFESSORES EM PORTUGAL NO QUADRO DO ESPAÇO EUROPEU DE ENSINO SUPERIOR. Revista Observatório, v. 3, n. 6, p. 3874, 1 out. 2017.

NUNES, S. G.; PORTO JUNIOR, F. G. R.; MORAES, N. R. DE. CONHECIMENTO E ORGANIZAÇÃO: indicativos pós-Bolonha de uma sociedade em construção. Revista Observatório, v. 3, n. 6, p. 338-353, 1 out. 2017.

PAULINO, R. DE C. R.; EMPINOTTI, M. L. PRODUTOS JORNALÍSTICOS PARA TABLETS COMO FERRAMENTAS PEDAGÓGICAS: estudo de caso do Golpe de 1964. Revista Observatório, v. 3, n. 6, p. 636-657, 1 out. 2017.

PÉREZ, S. I.; AYMÁ, A. M. MEDIOS, MULTIMODALIDAD, GÉNERO Y POLÍTICA: Cristina Fernández de Kirchner en Noticias. Revista Observatório, v. 3, n. 6, p. 517-556, 1 out. 2017.

PINHO, M. J. DE. UNIVERSIDADE E CRISE INSTITUCIONAL: perspectivas de uma formação humana. Revista Observatório, v. 3, n. 6, p. 274-315, 1 out. 2017.

PORTO JUNIOR, F. G. R.; MORAES, N. R. DE. FORMANDO PESQUISADORES PÓS-BOLONHA EM PORTUGAL: relações entre a formação de graduação e o campo da pesquisa/investigação. Revista Observatório, v. 3, n. 6, p. 202-228, 1 out. 2017.

PRIOR, H. A ECONOMIA DA ATENÇÃO DO ESCÂNDALO POLÍTICO. Revista Observatório, v. 3, n. 6, p. 586-611, 1 out. 2017.

REIS, E. G. DOS. O ENSINO SUPERIOR EM CABO VERDE E OS DESAFIOS DO PROCESSO DE BOLONHA. Revista Observatório, v. 3, n. 6, p. 142-168, 1 out. 2017.

SANTOS, E. R. DOS; GUAZINA, L. S. O USO DAS FONTES NAS NOTÍCIAS SOBRE O PROCESSO DE IMPEACHMENT: uma análise da cobertura realizada pelos jornais Folha de S. Paulo e a Tarde (BA). Revista Observatório, v. 3, n. 6, p. 612-635, 1 out. 2017.

SANTOS, J. L. DA C. DA PORTA AO PORTAL: o espaço como metáfora da narrativa jornalística. Revista Observatório, v. 3, n. 6, p. 680-697, 1 out. 2017.

TEIXEIRA, I.; DA SILVA, V. C.; MARTINS, J. L. A CONVERGÊNCIA MIDIÁTICA E AS TECNOLOGIAS MÓVEIS PÓS-BOLONHA: NOVAS PRÁTICAS SOCIAIS. Revista Observatório, v. 3, n. 6, p. 229247, 1 out. 2017.

THURLER, A. L. FEMINICÍDIOS NA MÍDIA E DESUMANIZAÇÃO DAS MULHERES. Revista Observatório, v. 3, n. 6, p. 465-496, 1 out. 2017. 